\title{
III. Remarks on the Rev. B. Bronwin's method for differential equations
}

\section{George Boole Esq.}

To cite this article: George Boole Esq. (1847) III. Remarks on the Rev. B. Bronwin's method for differential equations, Philosophical Magazine Series 3, 30:198, 6-8, DOI: $10.1080 / 14786444708562613$

To link to this article: http://dx.doi.org/10.1080/14786444708562613

曲 Published online: 30 Apr 2009.

Submit your article to this journal $\pi$

Џll Article views: 2

Q View related articles $₫$ 


\section{Mr. G. Boole on a Method for Differential Equations.}

received, and in it are accounts of two other meteors observed at Dijon on the 17th of October and on the 9th of November. M. Méline describes the latter in words which would almost exactly represent the phænomenon which $I$ have attempted, so imperfectly however, to place on record.

"Je sortais des serres du jardin, quand j’ai été frappé tout à coup d'une lumière aussi intense que celle du jour; j'aperçus distinctement toutes les parties du jardin, les arbustes comme les arbres, les plantes, etc. Je vis tout avec une teinte jaune serin. D'abord je crus à un incendie; mais, en jetant les yeux au ciel, $j$ 'ai vu un globe de feu se mouvant plus lentement qu'une fusée, de l'ouest à l'est, horizontalement, à 60 ou 70 degrés de hauteur. Le météore a laissé, sur toute la longueur de la route qu'il a suivie, une jmmense traînée d'un blanc couleur de cendre."

III. Remarks on the Rev. B. Bronwin's Method for Differential Equations. By George Boole, Esq.

To the Editors of the Philosophical Magazine and Journal. Gentumane,

I DESIRE very briefly to notice an error into which the 1 Rev. B. Bronwin has fallen, in a paper on the Integration and Transformation of certain Differential Equations, published in the last Number of the Philosophical Magazine.

In doing this I shall adopt a notation which I have before employed in a similar description of analysis, and which has the advantages of brevity and simplicity. Changing for convenience $p$ into $m$ and $y$ into $u$, we may observe that $\mathrm{Mr}$. Bronwin's transformations depend in all cases on the properties of two compound factors, which we shall designate by $\pi_{m}$ and $\rho$, and which, upon whatever subject they may operate, combine in subjection to the relation

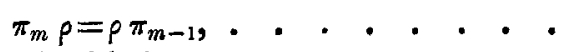

the equation to be solved being

$$
\pi_{m} u=0 \text {. . . . . . . . }
$$

Thus, in Mr. Bronwin's first equation, $\mathrm{D}$ standing for $\frac{d}{d x}$, in the second,

$$
\pi_{m}=x\left(\mathrm{D}^{2}+k^{2}\right)+2 m \mathrm{D}, \rho=\mathrm{D}^{2}+k^{2} ; . .
$$
in the third,

$$
\pi_{m}=\mathrm{D}^{2}+k x \mathrm{D}-m k, \rho=\mathrm{D}+k x ; . . .
$$

$$
\pi_{m}=x\left(\mathrm{D}^{3}+k^{3}\right)+3 m \mathrm{D}, \rho=\mathrm{D}^{3}+k^{3} ; . .
$$

and so on for the rest. 
Mr. G. Boole on a Method for Differential Equations. 7

Now (1.) gives $\quad \pi_{m} \rho v=\rho \pi_{m-1} v$,

whatever $v$ may be; let $\rho v=u$, then $v=\rho^{-1} u$, and we have

$$
\pi_{m} u=\rho \pi_{m-1} \rho^{-1} u
$$

so that the symbol $\pi_{m}$ is equivalent in operation to the compound symbol $\rho \pi_{m-1} \rho^{-1}$; writing then $\pi_{m-1}=\rho \pi_{m-2} \rho^{-1}$, we have

and finally,

$$
\begin{aligned}
& \pi_{m} u=\rho^{2} \pi_{m-2} \rho^{-2} ; \\
& \pi_{m} u=\rho^{m} \pi_{0} \rho^{-m} u .
\end{aligned}
$$

Hence the equation $\pi_{m} u=0$ gives

$$
\begin{aligned}
& \quad \rho^{m} \pi_{0} \rho^{-m} u=0 ; \\
& \therefore u=\rho^{m} \pi_{0}^{-1} \rho^{-m} 0 . \quad \text {. . . . . }
\end{aligned}
$$

This equation is unquestionably true, whatever may be the interpretation of the symbols $\pi_{m}$ and $\rho$, provided that they satisfy the combination law (1.).

Now taking Mr. Bronwin's first equation, viz.

$$
x\left(\mathrm{D}^{2}+k^{2}\right) u+2 m \mathrm{D} u=0 \text {, }
$$

and making $\pi_{m}=x\left(\mathrm{D}^{2}+k^{2}\right)+2 m \mathrm{D}, \rho=\mathrm{D}^{2}+k^{2}$,

we have

whence (6.) gives

$$
\pi_{0}=x\left(\mathrm{D}^{2}+k^{2}\right) \text {, }
$$

$$
u=\left(\mathrm{D}^{2}+k^{2}\right)^{m}\left\{x\left(\mathrm{D}^{2}+k^{2}\right)\right\}^{-1}\left(\mathrm{D}^{2}+k^{2}\right)^{-m} 0 .
$$

But

$$
\left\{x\left(\mathrm{D}^{2}+k^{2}\right)\right\}^{-1}=\left(\mathrm{D}^{2}+k^{2}\right)^{-1} x^{-1} \text {, }
$$

therefore $\quad u=\left(\mathrm{D}^{2}+k^{2}\right)^{m-1} x^{-1}\left(\mathrm{D}^{2}+k^{2}\right)^{-m} 0$.

Without entering into any special examination of the above result, and merely resting on the analogy of many similar cases, I should at once assert that, when $m$ is greater than 0 , we ought to retain two of the constants which arise from the performance of the inverse operation $\left(D^{2}+k^{2}\right)^{-m} 0$, and that it is not necessary that we should retain more than two. Thus one form of solution is unquestionably

$$
u=\left(\mathrm{D}^{2}+k^{2}\right)^{m-1} x^{-1}\left(c \cos k x+c^{\prime} \sin k x\right) ;
$$

and there are, I believe, many equivalent forms. The nature of Mr. Bronwin's error consists in his virtually rejecting the factors $x^{-1}$ and $\cos k x+c^{\prime} \sin k x$, and his result is accordingly nugatory whenever $m>0$. Similar remarks apply to the other equations in his paper, of which however I have only examined a small number in detail.

Perhaps, in connexion with this subject, it may not be quite irrelevant to mention, that about two years since I obtained the solution of the purely symbolical equation

$$
\pi_{m} \pi_{n} u+q \rho u=0
$$


in which, beside the law of combination,

the further condition was imposed,

$$
\pi_{m} \rho=\rho \pi_{m+1}, \pi_{n} \rho=\rho \pi_{n+1},
$$

$$
\pi_{m} \pi_{n}=\pi_{n} \pi_{m}-a(m-n) \rho .
$$

'Ihis solution, which will appear in the Cambridge and Dublin Mathematical Journal for January 1847, involves the solution of a class of differential equations of which that of Laplace's functions is only a very particular case. Such methods, limited in their individual application, and apparently indefinite in their number, seem however to be chiefly valuable as exercises in symbolical algebra. Linear differential equations, and linear equations in finite differences, may, as I have elsewhere shown, be reduced to the general form

$$
u+\varphi_{1}(\pi) \rho u+\varphi_{2}(\pi) \rho^{2} u \ldots=\mathrm{U},
$$

in which $\pi$ and $\rho$ satisfy the relations $f(\pi) \rho u=\rho f(\pi+1) u$ and $f(\pi) \rho^{m}=f(m) \rho^{m}$; and additional experience confirms my belief, that the methods which are founded on the employment of this form are sufficient for every case. Mr. Bronwin's equations, when thus treated, are at once seen to be integrable.

It is but justice to add, that Mr. Bronwin's method displays considerable ingenuity.

Lincoln, Dec. 4, 1846.

I remain, Gentlemen,

Your obedient Servant, George Boole.

IV. Observations on the Rev. B. Bronwin's Paper on the Integration and Transformation of certain Differential Equations. By Charles James Hargreave, F.R.S.

To the Editors of the Philosophical Magazine and Journal. Gentlemen,

TAKE the liberty of drawing your attention to an error 1 which appears to exist in the paper contained in your December Number on the Integration and Transformation of certain Differential Equations.

I confine my observations in the first place to the first of the equations discussed by the author; but it will be seen that the same or similar remarks are applicable to the other equations.

The solution of the equation

$$
x\left(\frac{d^{2} y}{d x^{2}}+k^{2} y\right)+2 p \frac{d y}{d x}=0 \quad \text {. . . }
$$

